\title{
Predictive performances of lipid accumulation product vs. adiposity measures for cardiovascular diseases and all-cause mortality, 8.6-year follow- up: Tehran lipid and glucose study
}

Mohammadreza Bozorgmanesh ${ }^{1 \dagger}$, Farzad Hadaegh ${ }^{1 *+}$, Fereidoun Azizi ${ }^{2 \dagger}$

\begin{abstract}
Background: The body mass index (BMI) is the most commonly used marker for evaluating obesity related risks, however, central obesity measures have been proposed to be more informative. Lipid accumulation product (LAP) is an alternative continuous index of lipid accumulation. We sought in this study to assess if LAP can outperform BMI, waist-to-height-ratio (WHtR), or waist-to-hip-ratio (WHpR) in predicting incident cardiovascular disease (CVD) or all-cause mortality.
\end{abstract}

Results: Among participants of Tehran Lipid and Glucose Study, 6,751 participants (2,964 men), aged $\geq 30$ years, were followed for a median of 8.6 years. We observed 274 deaths (men: 168) and 447 CVD events (men: 257). Levels of common CVD risk factors significantly increased across LAP quartiles. Mortality rates did not differ by LAP quartiles. Among participants free of CVD at baseline [6331 (2,741 men)], CVD incident rates per 1000 person increased in a stepwise fashion with increasing LAP quartile values in both men (from 6.9 to 17.0) and women (from 1.3 to 13.0), (Ps < 0.001).

Among women, a 1-SD increment in log-LAP conferred a 41\% increased risk for CVD (HR 1.41, 95\% Cls 1.02-1.96). Among men, however, LAP was not observed to be independently associated with increased risk of CVD; except in a sub-group of men assigned to the lifestyle modification interventions, where, LAP predicted CVD risk.

After adjustment with CVD risk factors LAP turned to be inversely associated with risk of all-cause mortality (HR, men 0.74 , 95\% Cls 0.61-0.90; women, 0.94 95\% Cls 0.74-1.20).

Among women, magnitude of increased risk of CVD due to LAP was not different from those of anthropometric measures. Among men, however, WHpR was observed to be more strongly associated with increased risk of CVD than was LAP.

Among neither men nor women were the predictive performances (discrimination, calibration, goodness-of-fit) of the LAP better than those of different anthropometric measures were.

Conclusions: If LAP is to be used for predicting CVD, it might not be superior to WHtR or WHpR.

\section{Background}

In his seminal 1988 Banting award lecture, Reaven introduced insulin resistance as a fundamental "disorder" associated with a set of metabolic abnormalities contributed to the development of cardiovascular

\footnotetext{
* Correspondence: fzhadaegh@endocrine.ac.ir

† Contributed equally

'Prevention of Metabolic Disorders Research Center, Research Institute for Endocrine Sciences (RIES), Shahid Beheshti University (M.C.), Tehran, Iran Full list of author information is available at the end of the article
}

disease (CVD) [1]. Large prospective studies [2-7] have shown that insulin resistance is a predictor of coronary artery disease (CAD). It is also relevant to mention that as Reaven found insulin resistant individuals who were not obese, he did not include obesity as a feature of the insulin resistance syndrome. Since then, a plethora of studies increasingly recognized insulin resistance, assessed by various methods, to be underlying factor associated with clustering atherogenic abnormalities [8]. Measuring indices of insulin sensitivity could not be

\section{() Biomed Central}


justified, practically in clinical setting. Some organizations, thus, have proposed the "metabolic syndrome (MetS)," a constellation of simple clinical parameters with cut-off values, to find individuals who would probably be insulin resistant [9-14]. Since then, a clinical diagnosis of the MetS was frequently shown to be associated with an increased risk of CVD [8]. It is well-documented that obesity is associated with insulin resistance [8]. However, obesity is remarkably heterogeneous as some obese patients are insulin sensitive whereas others are insulin resistant [15]. With remarkable heterogeneity of obesity in mind, measuring an index of abdominal adiposity such as the waist circumference (WC) is clinically relevant, since among obese individuals, there is a subgroup of abdominally obese patients who are more likely to be insulin resistant [8]. With the introduction of the MetS, the abdominal obesity was recognized as a clinically measurable (although imperfect) entity [8,16-18]. "An Increased WC, however, does not always mean high-risk visceral obesity [8]." WC cannot distinguish visceral adiposity, an important correlate of metabolic abnormalities, from the amount of subcutaneous abdominal fat. On the other hand, as an alternative to MetS, a more fundamental syndromic concept has been introduced. It might be defined by the limited capacity of the human body to buffer and dispose of lipid fuels. During periods of lipid excess, along with expansion of visceral adipocytes, the blood concentrations of certain lipids would become chronically elevated. This state, referred to as "lipid overaccumulation [19] could lead to ectopic deposition of lipids in non-adipose tissues, where insulin resistance and other metabolic dysfunctions would arise [20-22]. Some clinicians therefore used triglyceride (TGs) along with WC (hypertriglyceridemic waist) to find obese patients with abdominal obesity [23]. Lipid accumulation product (LAP), based on a combination of WC and the fasting concentration of circulating TG has recently been introduced by Kahn et al [20]. WC and TGs are each continuously associated with insulin resistance and cardiovascular risk [8]. Against hypertriglyceridemic waist that serve as a dichotomous risk marker $[22,23]$, the LAP was developed to express a continuous risk function [21].

LAP has been shown to predict incident diabetes [24] and all cause mortality [25]. Whether increased LAP confers an excess risk of CVD or not has not directly been addressed. Less is known concerning the performance of LAP as compared to the measures of general and abdominal adiposity. Our primary focus in this study, therefore, was to assess if LAP can outperform $\mathrm{BMI}$, waist-to-height ratio (WHtR), or waist-to-hip ratio (WHpR) in predicting incident CVD.

\section{Methods}

\section{Study population}

Detailed descriptions of the Tehran lipid and glucose study (TLGS) have been reported elsewhere [26]; in brief, the TLGS is a large scale, long term, communitybased prospective study performed on a representative sample of residents of district No. 13 of Tehran, capital of Iran. Age and sex distributions of the population in the district were representative of the overall population of Tehran at the time of the baseline examination. A total of 27,340 residents were invited by telephone call, of which 15,005 residents $(54.9 \%)$ aged $\geq 3$ years participated. The TLGS has two major components: a crosssectional prevalence study of non-communicable disease and associated risk factors, implemented between March 1999 and December 2001, and a prospective follow-up study. Data collection is ongoing, designed to continue for at least 20 years, at 3-year intervals. Participants were categorized into the cohort $(\mathrm{n}=9375)$ and intervention groups $(n=5630)$, the latter to be educated for implementation of life style modifications. For the current study, of those aged $\geq 30(n=8,071)$, we selected those who participated in the follow-up study until 10 March 2009 ( $\mathrm{n}=7,133)$. After exclusions (382 missing data), 6,751 (2,964 men) participants remained eligible (response rate 95\%). At the time of this study, the median follow up time was 8.7 years. Participants were provided with information regarding the result of their examinations and were given suitable advice. Informed written consent was obtained from all participants and the ethical committee of the Research Institute for Endocrine Sciences approved this study.

\section{Clinical and laboratory measurements}

A trained interviewer collected information using a pretested questionnaire. The information obtained included demographic data, family history of premature CVD, past medical history of CVD, and smoking status. Weight was measured, with subjects minimally clothed without shoes, using digital scales (Seca 707: range 0.1$150 \mathrm{~kg}$ ) and recorded to the nearest $100 \mathrm{~g}$. Height was measured in a standing position without shoes, using tape meter while shoulders were in a normal alignment. Waist circumference (WC) was measured at the umbilical level and that of the hip at the maximum level over light clothing, using an unstretched tape meter, without any pressure to body surface and measurements were recorded to the nearest $0.1 \mathrm{~cm}$ [27]. BMI $\left(\mathrm{kg} \cdot \mathrm{m}^{-2}\right)$ was calculated as weight $(\mathrm{kg})$ divided by square of the height $\left(\mathrm{m}^{2}\right)$. WHpR was calculated as WC $(\mathrm{cm})$ divided by hip circumference $(\mathrm{cm})$ and WHtR was calculated as WC divided by height $(\mathrm{cm})$. After a 15-minute rest in the sitting position, two measurements of blood pressure were 
taken, on the right arm, using a standardized mercury sphygmomanometer (calibrated by the Iranian Institute of Standards and Industrial Researches); the mean of the two measurements was considered as the participant's blood pressure.

A blood sample was drawn between 7:00 and 9:00 AM from all study participants, after 12 to 14 hours overnight fasting. All the blood analyses were undertaken at the TLGS research laboratory on the day of blood collection. Plasma glucose was measured using an enzymatic colorimetric method with glucose oxidase. Fasting plasma glucose (FPG) measurement was performed for all participants, and the standard 2-hour post-challenge plasma glucose (2h-PCPG) test for those not on glucose-lowering drugs. Total cholesterol (TC) was assayed, using the enzymatic colorimetric method with cholesterol esterase and cholesterol oxidase. High-density lipoprotein cholesterol (HDL-C) was measured after precipitation of the apolipoprotein B containing lipoproteins with phosphotungistic acid. TGs were assayed using enzymatic colorimetric assay with glycerol phosphate oxidase. Analyses were performed using Pars Azmon kits (Pars Azmon Inc., Tehran, Iran) and a Selectra 2 auto-analyzer (Vital Scientific, Spankeren, Netherlands). All samples were analyzed when internal quality control met the acceptable criteria. The intra and inter-assay coefficients of variation were both $<2.2 \%$ for plasma glucose, and 0.5 and $2 \%$ for TC, respectively [26].

\section{Outcome measurements}

Details of cardiovascular outcomes have been published elsewhere [28]. In this ongoing study every TLGS' participant is followed up for any medical event during the previous year, by telephone. They are questioned by a trained nurse regarding any medical conditions or whether a related event have occurred, a trained physician collects complementary data during a home visit and/or a visit to the respective hospital to collect data from the participants medical files. In the case of mortality, data are collected from the hospital or the death certificate by an authorized local physician. Collected data are evaluated by an outcome committee consisting of a principal investigator, an internist, an endocrinologist, a cardiologist, an epidemiologist, and the physician who collects the outcome data. Other experts are invited for evaluation of non-communicable disorders, as needed. A specific outcome for each event is assigned according to International Statistical Classification of Diseases and Related Health Problems criteria, 10th Revision, and American Heart Association classification for cardiovascular events $[26,29,30]$. Coronary heart disease (CHD) includes cases of definite myocardial infarction (MI) diagnosed by electrocardiogram (ECG) and biomarkers, probable MI (positive ECG findings plus cardiac symptoms or signs and biomarkers showing negative or equivocal results), unstable angina pectoris (new cardiac symptoms or changing symptom patterns and positive ECG findings with normal biomarkers), angiographic proven CHD and CHD death. CVD is specified as a composite measure of any CHD events, stroke, or cerebrovascular death.

\section{Definition of terms}

Lipid accumulation product (LAP) is an alternative continuous index of lipid accumulation, which is computed from WC $(\mathrm{cm})$ and TGs $\left(\mathrm{mmol}^{-1}\right)$ : (WC-65) $\times$ TG (men) and (WC-58) $\times$ TG (women). A previous history of CVD reflected any prior diagnosis of CVD by a physician. The family history of CVD was obtained by asking participants whether any member in their immediate family (first-degree relatives) had experienced a fatal or nonfatal MI, stroke or sudden cardiac arrest. The event was considered premature if it occurred before the age of 55 years in male relatives and before 65 in female relatives [31]. Current smoker was defined as a person who smokes cigarettes daily or occasionally. The diagnosis of hypertension was made in participants who self reported antihypertensive drug usage or in those with the average of the two diastolic blood pressure measurements was $\geq 90 \mathrm{mmHg}$ or when the average of the two systolic blood pressure measurements was $\geq 140 \mathrm{~mm}$ $\mathrm{Hg}$ [32]. High cholesterol was ascertained in those with total cholesterol $\geq 5.2 \mathrm{mmol}^{-1}$, high TGs in those with TGs $\geq 1.7 \mathrm{mmol}^{-1} \mathrm{l}^{-1}$ and low HDL-C in men with HDL$\mathrm{C}<1.03 \mathrm{mmol} . \mathrm{l}^{-1} \mathrm{l}$ and in women with HDL-C $<1.29$ mmol. $1^{-1}$ [33]. Participants using oral hypoglycemic agents or insulin were considered as having diabetes. Diabetes was also ascertained in participants with FPG $\geq 7.0 \mathrm{mmol} . \mathrm{l}^{-1}$ or $2 \mathrm{~h}-\mathrm{PCPG} \geq 11.1 \mathrm{mmol.l^{-1 }}$ [34]. NonHDL- $C$ was calculated by subtracting HDL-C from total cholesterol.

\section{Statistics analysis}

Findings on covariate variables are expressed as means (SD) or percentages for continuously distributed and categorical variables, respectively. We tested for trends across LAP quartiles by using the median in each quartile as a predictor, separately for each sex. The General Linear Model was developed for continuous variables, and the Cox proportional hazards regression model was used for incidence rates. Models were adjusted for age.

For each participant, free of CVD at baseline, the baseline 10-year risk of CVD was calculated using the Framingham's "general CVD risk prediction algorithm [35]." We divided the study sample into those with high and low global risk of CVD. Then, in each sub-group, Kaplan-Meier survival curves were plotted to 
demonstrate the risk of CVD for each sex across LAP quartiles. The Log-Rank test was performed to examine the significance of trends across LAP quartiles.

When CVD was considered as outcome another 521 prevalent CVD cases were also excluded from the analysis leaving a final sample of 6,331 participants (2741 men). In the analysis of CVD outcome, LAP, BMI, WHpR, and WHtR were assessed using Cox proportional hazards regression analyses. Survival time was the time from start of the follow-up period to the date of the first incident, CVD event, or death due to any cause (failure). The censoring time of an individual was the time from entry into the study to loss to follow-up or the end of the study, whichever happened first. Censored observation meant the subject either refused to participate further in the study (lost to follow-up), died, when death was not the study outcome (competing risk) or continued until the study was ended (administrative censoring). Valid comparison of hazards ratios (HRs) for different continuous measures requires that the units of both variables to be comparable. We, thus, estimated sex-specific hazard ratios (HRs), with 95\% confidence intervals (CI) for follow-up events for an one SD increment in natural log-transformed LAP and each respective anthropometric parameter. HRs were adjusted for age, smoking, systolic blood pressure, family history of premature CVD, diabetes, antihypertensive drug usage, HDL and non-HDL cholesterol, FPG, and 2h-PCPG [31], plus the TLGS intervention measures.

We also examined if the effects of LAP on incident CVD or all-cause mortality has been modified by different levels of risk ( $<20$ vs. $\geq 20 \%$ ) [35] or life style modification measures. We introduced interaction terms between LAP and global CVD risk levels and LAP and intervention assignment status.

Wald tests of the linear hypotheses concerning the Cox regression models coefficients (paired homogeneity test) were performed to test the null hypotheses that the hazard ratios (effect size) for LAP were equal to those for anthropometric measures.

We compared predictive performance of the LAP with those of the studied anthropometric variables with respect to discrimination, calibration, and goodness-offit.

Discrimination is the ability of a prediction model to separate those who develop diabetes events from those who do not and is quantified by the $C$ statistic [36]. In the survival analysis, $C$ statistic [37] measures the probability that a randomly selected person who developed an event, at the certain specific time has a higher risk score than a randomly selected person who did not develop an event during the same, specific follow-up interval [38].
Calibration, as it is phrased in reference [39] describes how closely predicted probabilities agree numerically with actual outcomes $[40,41]$. A test very similar to the Hosmer-Lemeshow test has been proposed by Grønnsby and Borgan, which is based on sum of martingale residuals within groups that have been developed by partitioning the data based on the estimated risk score $\left(x^{\prime} \beta\right)$ $[42,43]$. Following May and Hosmer we calculated the test statistic using score test $\left(\chi^{2}\right)$ for the inclusion of G1 reference cell design variables $[41,44,45]$.

How effectively a model describes the outcome variable is referred to as its goodness-of-fit. Akaike information criterion (AIC) was used as a measure of model fit and informativeness indicating whether the addition of new factors to a base model provides better risk prediction than the base model alone, provided that all of the same individuals are being assessed by both models [46]. When estimating model parameters using maximum likelihood estimation, it is possible to increase the likelihood by adding parameters, which may result in over-fitting. The Bayesian information criterion (BIC) resolves this problem by introducing a penalty term for the number of parameters in the model. It is very closely related to the AIC. In BIC, the penalty for additional parameters is stronger than that of the AIC [47].

Because BMI, WHpR, WHtR, and LAP were highly correlated, we assessed collinearity between these variables using condition indices and variance inflation factor (VIF). Condition indices $>30$ or VIFs $>10$ warrant caution [48].

We certify that all applicable institutional and governmental regulations concerning the ethical use of human volunteers were followed during this research. Informed written consent was obtained from all participants and the Ethical Committee of Research Institute for Endocrine Sciences approved this study.

We set the statistical significance level at a two-tailed type I error of 0.05 . All statistical analyses were performed using STATA 10.0.

\section{Result}

During follow up (men: 24,209 person-year; women: 31,454 person-year), 274 deaths (men: 168; women: 106) and 447 CVD events (men: 257; women: 190) occurred. The major causes of death were fatal CVD events $(36.6 \%)$, cancers $(11.7 \%)$, diabetes complications $(4.7 \%)$, trauma $(4.4 \%)$, and infectious disease (3.3). CVD incident rates among participants who were assigned to life style modification measures (men: 10.6, 95\% CIs 8.7-13.1; women: 6.2, 95\% CIs 4.9-7.8) was not different from those who were not (men: $12.4,95 \%$ CIs 10.6-14.4; women: 6.6, 95\% CIs 5.5-7.9). Mortality rates were also the same in the intervention group 
Table 1 Baseline characteristics across quartiles of lipid accumulation product among men

\begin{tabular}{|c|c|c|c|c|c|}
\hline & $\begin{array}{c}\text { Q1 } \\
\left.\text { (cm.mmol. }\left.\right|^{-1}\right) \\
<2288\end{array}$ & $\begin{array}{c}\left.\text { Q2 (cm.mmol.. }\left.\right|^{-1}\right) \text { 2289- } \\
4186\end{array}$ & $\begin{array}{c}\text { Q3 (cm.mmol.I } \text { I }^{-1} \text { ) 4192- } \\
6900\end{array}$ & $\begin{array}{c}\left.\text { Q4 (cm.mmol. } .^{-1}\right) 6912- \\
57000\end{array}$ & $\begin{array}{l}P \text { for } \\
\text { trends }^{\dagger}\end{array}$ \\
\hline Number of participants* & 741 & 741 & 742 & 740 & \\
\hline Age (years) & $48.1(14.4)$ & 49.1(13.6) & $50.7(13.0)$ & $49.2(12.5)$ & \\
\hline $\mathrm{SBP}(\mathrm{mmHg})$ & 117.2(19.8) & 122.0(19.3) & 126.8(20.9) & 127.6(19.0) & $<0.001$ \\
\hline $\mathrm{DBP}(\mathrm{mmHg})$ & $73.9(11.5)$ & $77.9(10.6)$ & 81.1(11.2) & $82.0(11.2)$ & $<0.001$ \\
\hline MAP (mmHg) & 88.3(12.8) & $92.6(12.2)$ & $96.4(13.1)$ & $97.2(12.6)$ & $<0.001$ \\
\hline Pulse pressure $(\mathrm{mmHg})$ & $43.3(16.1)$ & $44.1(15.0)$ & $45.7(16.0)$ & $45.5(14.1)$ & $<0.001$ \\
\hline Pulse (beat per minute) & $73.1(10.0)$ & 73.6(9.9) & $75.1(9.5)$ & $76.3(9.7)$ & $<0.001$ \\
\hline BMI $\left(\mathrm{kg} \cdot \mathrm{m}^{-2}\right)$ & $22.4(2.8)$ & $25.7(2.7)$ & $27.6(2.8)$ & $29.3(3.5)$ & $<0.001$ \\
\hline Waist-to-hip ratio (\%) & $86.2(5.5)$ & $92.9(5.2)$ & $95.9(5.3)$ & $98.3(5.6)$ & $<0.001$ \\
\hline Waist-to-height ratio (\%) & $46.5(4.6)$ & $52.9(4.4)$ & $56.0(4.4)$ & $58.8(5.2)$ & $<0.001$ \\
\hline Lipid accumulation product & $11.4(2.2)$ & $35.9(1.2)$ & $60.3(1.2)$ & $117.9(1.4)$ & $<0.001$ \\
\hline Triglycerides (mmol. $\mathrm{I}^{-1}$ ) & $1.1(1.4)$ & $1.6(1.5)$ & 2.1(1.3) & $3.5(1.5)$ & $<0.001$ \\
\hline Total cholesterol (mmol.. $\left.{ }^{-1}\right)$ & $4.9(1.0)$ & $5.3(0.9)$ & $5.6(1.0)$ & $6.0(1.2)$ & $<0.001$ \\
\hline Non-HDL-C (mmol. I' $\left.{ }^{-1}\right)$ & $3.8(0.9)$ & $4.3(0.9)$ & 4.6(0.9) & $5.2(1.1)$ & $<0.001$ \\
\hline HDL-C (mmol..$\left.^{-1}\right)$ & $1.1(0.3)$ & $1.0(0.2)$ & $1.0(0.2)$ & $0.9(0.2)$ & $<0.001$ \\
\hline FPG $\left(m m o l . I^{-1}\right)$ & $5.2(1.4)$ & $5.4(1.5)$ & $5.6(1.7)$ & $6.1(2.3)$ & $<0.001$ \\
\hline 2h-PCPG (mmol..$\left.^{-1}\right)$ & $5.5(2.6)$ & $6.4(3.2)$ & $6.9(3.5)$ & $8.0(4.2)$ & $<0.001$ \\
\hline $\begin{array}{l}\text { Assignment to intervention } \\
\text { (\%) }\end{array}$ & $288(38.9)$ & $281(37.9)$ & $275(37.1)$ & $305(41.2)$ & 0.347 \\
\hline Diabetes & $59(8.0)$ & $76(10.3)$ & $146(19.7)$ & $205(27.7)$ & $<0.001$ \\
\hline Hypertension & $253(34.1)$ & $366(49.4)$ & $462(62.3)$ & $476(64.3)$ & $<0.001$ \\
\hline Smoking & $253(34.1)$ & $202(27.3)$ & $176(23.7)$ & $208(28.1)$ & 0.001 \\
\hline $\begin{array}{l}\text { Family history of premature } \\
\text { CVD }\end{array}$ & $49(6.6)$ & $58(7.8)$ & $70(4.9)$ & $61(8.2)$ & 0.223 \\
\hline Incident** CHD (95\% Cls) & $5.3(3.8-7.6)$ & $8.6(6.5-11.5)$ & $11.2(8.7-14.4)$ & 15.0(12.1-18.6) & $<0.001$ \\
\hline Incident** CVD (95\% Cls) & $6.9(5.1-9.4)$ & $10.1(7.8-13.2)$ & 13.2(10.4-16.6) & 17.0(13.8-20.8) & $<0.001$ \\
\hline Mortality** rate $(95 \%$ Cls) & $8.3(6.3-11.0)$ & 7.6(5.7-10.2) & $6.1(4.4-8.4)$ & $5.8(4.2-8.1)$ & 0.134 \\
\hline
\end{tabular}

BMI, body mass index; DBP, diastolic blood pressure; FPG, fasting plasma glucose; $\mathrm{HDL}$, high density lipoprotein cholesterol; MAP, mean arterial pressure 2hPCPG, 2-hour post-challenge plasma glucose; SBP, systolic blood pressure;

Continuous variables are represented as mean (standard deviation) except for triglycerides and lipid accumulation products that are represented as geometric mean (standard deviation of geometric mean). Categorical variables are represented as frequency (percent). Confidence intervals have been provided for incident rates.

**Per 1000 person per year

† P-values were calculated using general linear models, for continuous variables and Cox proportional hazards regression models for incidence rates. Models were sex-specific and age-adjusted.

(men: 6.3, 95\% CIs 4.8-8.1; women: 3.6 , 95\% CIs 2.64.8) and the cohort (men: 7.4, 95\% CIs 6.1-8.9; women, 3.3, CIs 2.5-4.2) (all Ps > 0.3). The prevalence of high TG, high total cholesterol, low HDL-C, hypertension, diabetes, family history of CVD, and prevalent CVD were $56.6,58.3,35.3,39.0,16.4,8.0$, and $7.5 \%$, among men and $52.7,66.1,25.5,39.6,17.7,12.1$, and $5.2 \%$ among women, respectively.

As shown in Table 1 and 2, levels of common CVD risk factors significantly increases across LAP quartiles, except for family history of premature CVD among men and smoking among both sexes. CVD incident rates per 1000 person increased in a stepwise fashion with increasing LAP quartile values in both men (from 6.9 to 17.0) and women (from 1.3 to 13.0), ( $\mathrm{P}$ for trends $<0.001)$. Mortality rates, however, remained unchanged across LAP quartiles.
Table 3 presents the contribution of LAP to the risk of CVD, independent of other CVD risk factors, separately for men and women.

Among women, a 1-SD (0.81) increment in log LAP conferred a $41 \%$ increased risk for CVD (HR 1.41, 95\% CI 1.02-1.96). Among men, however, LAP was not observed to be independently associated with increased risk of CVD. Multivariate adjusted hazard ratios for a 1SD increment in WC for CVD and all-cause mortality among men were 1.18 (95\% CIs 1.01-1.39, P = 0.036) and 0.90 (95\% CIs $0.72-0.1 .12, \mathrm{P}=0.348$ ), respectively; the corresponding figures among women were 1.24 (95\% CIs 1.03-1.49, $\mathrm{P}=0.021$ ) and 0.84 (95\% CIs 0.65$1.09, \mathrm{P}=0.197)$. Hazard ratios for a $1-\mathrm{SD}$ increment in TG for CVD and all-cause mortality among men were 1.00 (95\% CIs 0.88-1.1.41, P = 0.953) and 0.75 (95\% CIs $0.56-1.00, \mathrm{P}=0.055)$, respectively; the corresponding 
Table 2 Baseline characteristics across quartilesof lipid accumulation product among women

\begin{tabular}{|c|c|c|c|c|c|}
\hline & Q1 (cm.mmol. $\left.\left.\right|^{-1}\right)$ & Q2 (cm.mmol. $\left.\mathrm{I}^{-1}\right)$ 2755- & $\begin{array}{c}\text { Q3 }\left(\mathrm{cm} . \mathrm{mmol}^{-1} \mathrm{I}^{-1}\right) \text { 5043- } \\
8265\end{array}$ & $\begin{array}{c}\left.\text { Q4 (cm.mmol. }{ }^{-1}\right) \text { 8268- } \\
54948\end{array}$ & $\begin{array}{c}P \text { for } \\
\text { trends }^{\dagger}\end{array}$ \\
\hline Number of participants* & 947 & 954 & 939 & 947 & \\
\hline Age (years) & $40.6(10.4)$ & $46.5(11.7)$ & $49.9(11.6)$ & $52.1(10.8)$ & \\
\hline $\mathrm{SBP}(\mathrm{mmHg})$ & $112.7(15.7)$ & $120.9(18.7)$ & $127.7(21.8)$ & 133.2(21.9) & $<0.001$ \\
\hline $\mathrm{DBP}(\mathrm{mmHg})$ & 74.6(9.4) & $78.3(10.1)$ & $82.0(10.7)$ & $84.3(10.8)$ & $<0.001$ \\
\hline MAP $(\mathrm{mmHg})$ & $87.3(10.5)$ & $92.5(11.8)$ & $97.2(13.1)$ & $100.6(13.2)$ & $<0.001$ \\
\hline Pulse pressure (mmHg) & $38.1(11.8)$ & $42.5(14.5)$ & $45.7(16.8)$ & $48.9(16.8)$ & $<0.001$ \\
\hline Pulse (beat per minute) & $80.9(11.9)$ & $81.0(12.1)$ & $80.8(11.9)$ & $81.7(12.0)$ & $<0.012$ \\
\hline $\mathrm{BMI}\left(\mathrm{kg} \cdot \mathrm{m}^{-2}\right)$ & $24.7(3.5)$ & 27.9(3.6) & $29.9(4.2)$ & $31.7(4.5)$ & $<0.001$ \\
\hline Waist-to-hip ratio (\%) & $78.5(6.5)$ & $85.3(6.6)$ & $88.5(6.8)$ & $92.2(7.0)$ & $<0.001$ \\
\hline Waist-to-height ratio (\%) & $49.9(5.2)$ & $57.1(5.4)$ & $61.3(5.9)$ & $65.4(6.2)$ & $<0.001$ \\
\hline Lipid accumulation product & $17.8(1.6)$ & $42.9(1.2$ & $73.0(1.2)$ & $135.6(1.4)$ & $<0.001$ \\
\hline Triglycerides $\left(\right.$ mmol..$^{-1}$ ) & $1.0(1.4)$ & $1.4(1.3)$ & $2.0(1.3)$ & $3.2(1.4)$ & $<0.001$ \\
\hline Total cholesterol (mmol..$\left.^{-1}\right)$ & $5.0(1.0)$ & $5.5(1.0)$ & $6.0(1.1)$ & $6.5(1.3)$ & $<0.001$ \\
\hline Non-HDL-C (mmol..$\left.^{-1}\right)$ & 3.8(0.9) & $4.3(1.0)$ & $4.9(1.1)$ & $5.5(1.3)$ & $<0.001$ \\
\hline $\mathrm{HDL}-\mathrm{C}\left(\mathrm{mmol} . \mathrm{I}^{-1}\right)$ & $1.3(0.3)$ & $1.2(0.3)$ & $1.1(0.3)$ & $1.0(0.3)$ & $<0.001$ \\
\hline FPG $\left(m m o l . I^{-1}\right)$ & $5.0(1.3)$ & $5.3(1.6)$ & $5.9(2.3)$ & $6.5(2.8)$ & $<0.001$ \\
\hline $2 h-P C P G\left(m m o l . I^{-1}\right)$ & $5.8(1.8)$ & $6.5(2.3)$ & $7.4(3.2)$ & $8.7(4.2)$ & $<0.001$ \\
\hline $\begin{array}{l}\text { Assignment to intervention } \\
\text { (\%) }\end{array}$ & $362(38.2)$ & $387(40.6)$ & $363(38.7)$ & $365(38.5)$ & 0.657 \\
\hline Diabetes & $46(4.9)$ & $104(10.9)$ & $197(21.0)$ & $322(34.0)$ & $<0.001$ \\
\hline Hypertension & $288(28.3)$ & $472(42.5)$ & $585(62.3)$ & $699(73.8)$ & $<0.001$ \\
\hline Smoking & $44(4.7)$ & $37(3.9)$ & $30(3.2)$ & $28(3.0)$ & 0.748 \\
\hline $\begin{array}{l}\text { Family history of premature } \\
\text { CVD }\end{array}$ & $92(9.7)$ & $107(11.2)$ & $129(13.7)$ & $131(13.8)$ & $<0.010$ \\
\hline Incident** CHD (95\% Cls) & $1.1(0.6-2.2)$ & $3.6(2.4-5.2)$ & $7.4(5.7-9.7)$ & $11.2(8.9-14.0)$ & $<0.001$ \\
\hline Incident** CVD (95\% Cls) & $1.3(0.7-2.4)$ & $4.1(2.9-5.8)$ & $8.3(6.4-10.7)$ & $13.0(10.5-16.0)$ & $<0.001$ \\
\hline Mortality** rate $(95 \% \mathrm{Cls})$ & $2.4(1.5-3.7)$ & $2.5(1.6-3.9)$ & $4.1(2.9-5.8)$ & $4.5(3.3-6.3)$ & 0.673 \\
\hline
\end{tabular}

BMI, body mass index; DBP, diastolic blood pressure; FPG, fasting plasma glucose; $\mathrm{HDL}$, high density lipoprotein cholesterol; MAP, mean arterial pressure 2hPCPG, 2-hour post-challenge plasma glucose; SBP, systolic blood pressure;.

Continuous variables are represented as mean (standard deviation) except for triglycerides and lipid accumulation products that are represented as geometric mean (standard deviation of geometric mean). Categorical variables are represented as frequency (percent). Confidence intervals have been provided for incident rates.

**Per 1000 person per year

† P-values were calculated using general linear models, for continuous variables and Cox proportional hazards regression models for incidence rates. Models were sex-specific and age-adjusted.

figures among women were 0.98 (95\% CIs 0.80-1.20, $\mathrm{P}=$ 0.834 ) and 1.26 (95\% CIs $0.88-1.81, \mathrm{P}=0.206)$, respectively.

We failed to demonstrate any increased risk of allcause mortality owing to LAP (Table 4). In fact, after adjustment with CVD risk factors LAP turned to be inversely associated with risk of all-cause mortality. This association, however, was statistically significant among men (HR 0.74, 95\% CIs 0.61-0.90) but not among women (HRs 0.94 95\% CIs 0.74-1.20).

Figures 1, 2, 3, 4, 5, 6, 7, and 8 represent the sex-specific Kaplan-Meier curves for CVD and all-cause mortality, across LAP quartiles in the two sub-groups defined by baseline global CVD risk $\geq 20 \%$ and $<20 \%$. Among women with global CVD risk less than $20 \%$, the probability of remaining free of CVD decreased in stepwise fashion across LAP quartiles. Such a trend was not observed among women with global CVD risk of $20 \%$ or more. In the contrary, in men it was among those with global CVD risk $\geq 20 \%$ that the probability of remaining free of CVD across decreased across LAP quartiles. Kaplan-Meier survival curves plotted for all-cause mortality showed that survival prognosis improved in stepwise fashion across LAP quartiles among men, regardless of their baseline global CVD risk. Among women survival prognosis did not differ by LAP quartiles.

In multivariate-adjusted Cox proportional hazard regression models LAP predicted incident CVD only among women with global CVD risk less than 20\%, while it did not predict all-cause mortality in any of sub-groups (Table 5).

When we introduced interaction terms between intervention assignment status and LAP to the models, 
Table 3 Contribution of LAP to the risk of CVD, independent of common CVD risk factors among men and women

\begin{tabular}{|c|c|c|c|c|}
\hline & & & & \\
\hline & $\mathrm{HR}^{*}(95 \% \mathrm{Cls})$ & P-value & $\mathrm{HR}^{*}(95 \% \mathrm{Cls})$ & P-value \\
\hline Age (years) & $1.05(1.04-1.06)$ & $<0.001$ & $1.06(1.04-1.08)$ & $<0.001$ \\
\hline Smoking & $1.86(1.37-2.51)$ & $<0.001$ & $2.97(1.36-6.47)$ & 0.006 \\
\hline Premature history of CVD & $1.47(0.94-2.32)$ & 0.094 & $1.60(1.01-2.52)$ & 0.044 \\
\hline Diabetes & $1.30(0.81-2.08)$ & 0.271 & $1.95(1.13-3.35)$ & 0.017 \\
\hline Antihypertensive drug use & $1.42(0.97-2.08)$ & 0.068 & $2.04(1.40-2.98)$ & $<0.001$ \\
\hline Systolic blood pressure $(\mathrm{mmHg})$ & $1.40(1.24-1.58)$ & 0.000 & $1.23(1.04-1.46)$ & 0.014 \\
\hline Intervention & $0.76(0.57-1.01)$ & 0.059 & $0.96(0.67-1.38)$ & 0.842 \\
\hline Non-HDL-C (mmol..$\left.^{-1}\right)$ & $1.34(1.15-1.56)$ & $<0.001$ & $1.25(1.05-1.50)$ & 0.014 \\
\hline $\mathrm{HDL}-\mathrm{C}\left(\mathrm{mmol} \mathrm{I}^{-1}\right)$ & $0.81(0.67-0.97)$ & 0.022 & $1.06(0.88-1.28)$ & 0.547 \\
\hline FPG $\left(m m o l . I^{-1}\right)$ & $1.29(0.97-1.71)$ & 0.075 & $0.81(0.60-1.09)$ & 0.169 \\
\hline 2h-PCPG (mmol..$\left.^{-1}\right)$ & $0.97(0.79-1.20)$ & 0.800 & $1.10(0.90-1.35)$ & 0.342 \\
\hline 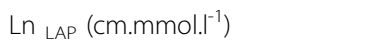 & $1.06(0.89-1.26)$ & 0.535 & $1.41(1.02-1.96)$ & 0.038 \\
\hline
\end{tabular}

* For one SD increment in each continuous predictor, obtained from multivariate Cox proportional hazards regression model adjusted for age, smoking, systolic blood pressure, family history of premature CVD, diabetes, antihypertensive drug usage, HDL and non-HDL cholesterol, FPG, and $2 \mathrm{~h}-\mathrm{PCPG}$, plus the TLGS intervention measures.

CVD, cardiovascular disease; FPG, fasting plasma glucose; HDL-C, high density lipoprotein cholesterol; HR, hazard ratio; LAP, lipid accumulation product; Ln, naturally logarithmically transformed; $2 \mathrm{~h}-\mathrm{PCPG}, 2$-hour post-challenge plasma glucose;

among both men and women the results remained essentially unchanged (Ps for interactions $>0.07$ ). Nonetheless, we examined the effects of LAP on risk of CVD and all-cause mortality separately for those who were assigned to the life style modification measures and those who were not (Tables 5). The finding of interest was that LAP conferred a $58 \%$ increase in the risk of CVD among men who were assigned to the life style modification interventions (HR 1.58, 95\% CIs 1.11-2.26). Among women CVD risk conferred by LAP for both sub-groups were similar to that of whole sample, though, no longer statistically significant. It may be due to the broadened $95 \%$ CIs and decreased statistical power.

Relative importance of LAP has been compared with those of anthropometric measures in Table 6. Among women, the magnitude of increased risk of CVD due to LAP was not different from those of anthropometric measures. Among men, however, WHpR was observed to be more strongly associated with increased risk of CVD than was LAP.

Table 6 represents the different measures of predictive performance of models incorporating LAP, BMI, WHpR, and WHtR, each at a time. Models

Table 4 Contribution of LAP to the risk of all-cause mortality, independent of common CVD risk factors among men and women

\begin{tabular}{|c|c|c|c|c|}
\hline & \multicolumn{2}{|c|}{ Men } & \multicolumn{2}{|c|}{ Women } \\
\hline & $\mathrm{HR}^{*}(95 \% \mathrm{Cls})$ & P-value & $\mathrm{HR}^{*}(95 \% \mathrm{Cls})$ & P-value \\
\hline Age (years) & $1.09(1.07-1.11)$ & $<0.001$ & $1.14(1.11-1.18)$ & $<0.001$ \\
\hline Smoking & $2.01(1.32-3.04)$ & 0.001 & $2.27(0.69-7.50)$ & 0.179 \\
\hline Premature history of CVD & $0.58(0.23-1.41)$ & 0.228 & $1.16(0.55-2.47)$ & 0.692 \\
\hline Diabetes & $1.52(0.86-2.69)$ & 0.151 & $1.30(0.51-3.34)$ & 0.579 \\
\hline Antihypertensive drug use & $1.97(1.31-2.98)$ & 0.001 & $1.59(0.92-2.74)$ & 0.094 \\
\hline Systolic blood pressure (mmHg) & $1.20(1.03-1.40)$ & 0.022 & $1.03(0.80-1.32)$ & 0.822 \\
\hline Intervention & $0.69(0.47-1.02)$ & 0.061 & $1.10(0.66-1.84)$ & 0.708 \\
\hline Non-HDL-C (mmol. I $\left.^{-1}\right)$ & $0.94(0.75-1.18)$ & 0.595 & $0.86(0.64-1.15)$ & 0.295 \\
\hline $\mathrm{HDL}-\mathrm{C}\left(\mathrm{mmol} . \mathrm{I}^{-1}\right)$ & $0.87(0.69-1.08)$ & 0.197 & $0.93(0.71-1.22)$ & 0.582 \\
\hline FPG $\left(m m o l . I^{-1}\right)$ & $1.19(0.82-1.72)$ & 0.366 & $0.67(0.34-1.32)$ & 0.253 \\
\hline 2h-PCPG (mmol..$\left.^{-1}\right)$ & $1.02(0.79-1.31)$ & 0.892 & $1.18(0.86-1.63)$ & 0.310 \\
\hline $\operatorname{Ln} \operatorname{LAP}\left(\mathrm{cm} . \mathrm{mmol} . \mathrm{I}^{-1}\right)$ & $0.74(0.61-0.90)$ & 0.003 & $0.88(0.60-1.30)$ & 0.530 \\
\hline
\end{tabular}

* For one SD increment in each continuous predictor, obtained from multivariate Cox proportional hazards regression model adjusted for age, smoking, systolic blood pressure, family history of premature CVD, diabetes, antihypertensive drug usage, HDL and non-HDL cholesterol, FPG, and $2 \mathrm{~h}-\mathrm{PCPG}$, plus the TLGS intervention measures.

CVD, cardiovascular disease; FPG, fasting plasma glucose; HDL-C, high density lipoprotein cholesterol; HR, hazard ratio; LAP, lipid accumulation product; Ln, naturally logarithmically transformed; $2 \mathrm{~h}$-PCPG, 2-hour post-challenge plasma glucose; 


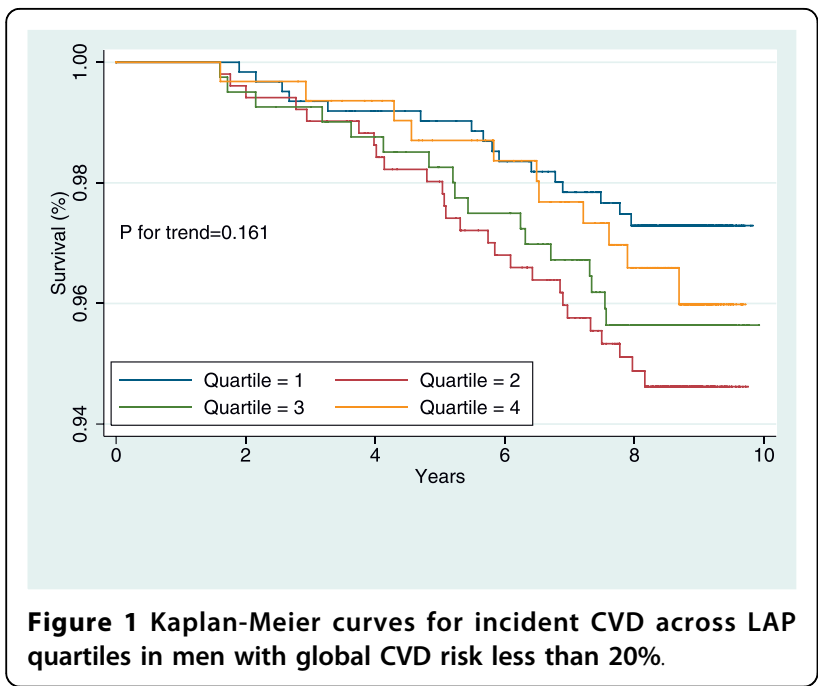

incorporating LAP and different anthropometric measures generally better fit the data among women (AICs 1872-1878, BIC 1945-1951) than among men (AICs 3128-3134, BIC 3198-3204). The discrimination capacities of the models were also higher among women (C statistics 0.846-0.849) than among men (C statistics 0.785-0.788). The model-based estimated risk of CVD again better agreed with observed risk among women (Hosmer-Lemeshow $\chi^{2}$ 11.9-12.8) than among men (Hosmer-Lemeshow $\chi^{2}$ 18.0-21.6). Among neither men nor women were the predictive performances of the LAP better than those of different anthropometric measures were.

\section{Discussion}

For the first time, using data from a community-based prospective study of men and women for a median of 8.6 years, we demonstrated that the LAP was

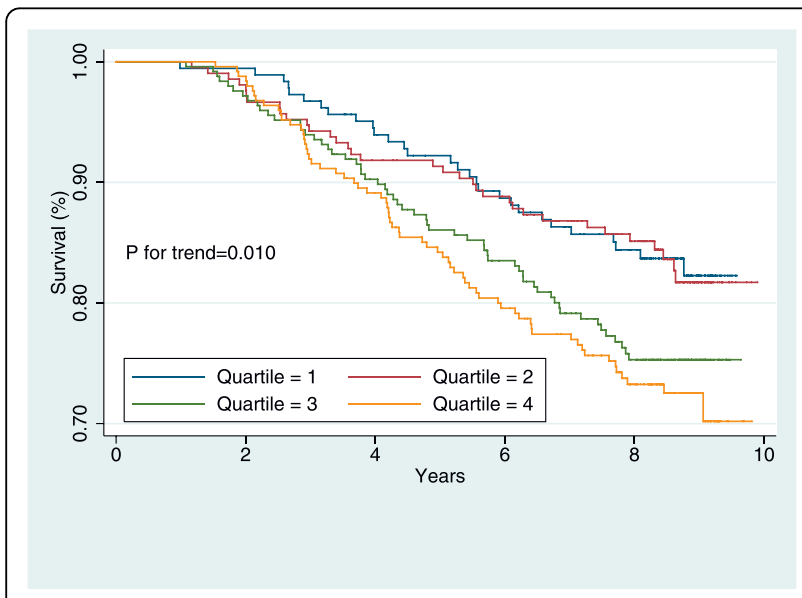

Figure 2 Kaplan-Meier curves for incident CVD across LAP quartiles in men with global CVD risk $20 \%$ or more.

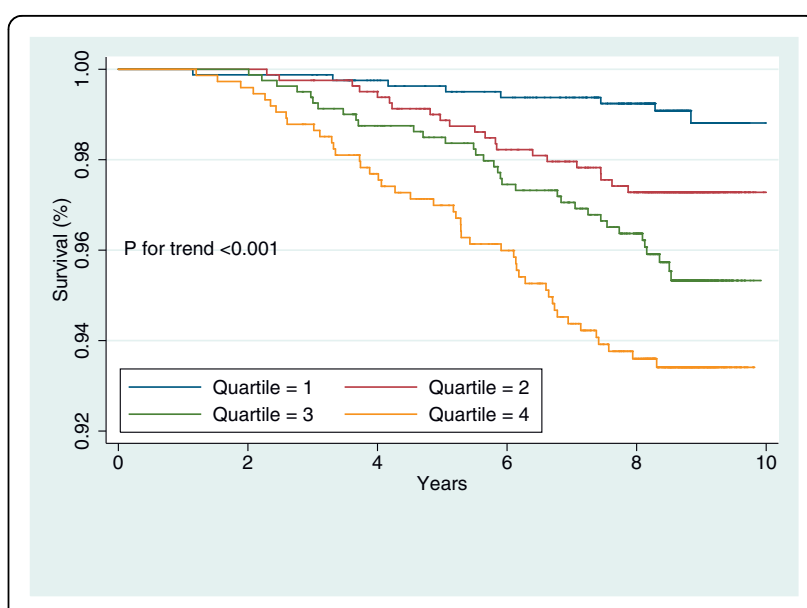

Figure 3 Kaplan-Meier curves for incident CVD across LAP quartiles in women with global CVD risk less than $20 \%$

independently associated with an increased risk of incident CVD among women and that the magnitude of this risk was not significantly higher than those conferred by BMI, WHpR, or WHtR. Among men, after controlling common CVD risk factors, we observed that LAP was not associated with any significant increased risk of incident CVD. The only exception observed was among a subgroup of men who were assigned to the life style modification interventions. In this sub-group a 1$\mathrm{SD}$ increment in naturally logarithmatically transformed LAP conveyed a 58\% increased CVD risk. Among men the magnitude of risk conferred by WHpR exceeded that of LAP. No associations were observed between the LAP and increased risk of all-cause mortality in men or women.

As a component of a multivariate predictive model for incident CVD, the LAP, BMI, WHpR, and WHtR had the same performance with respect to the discrimination

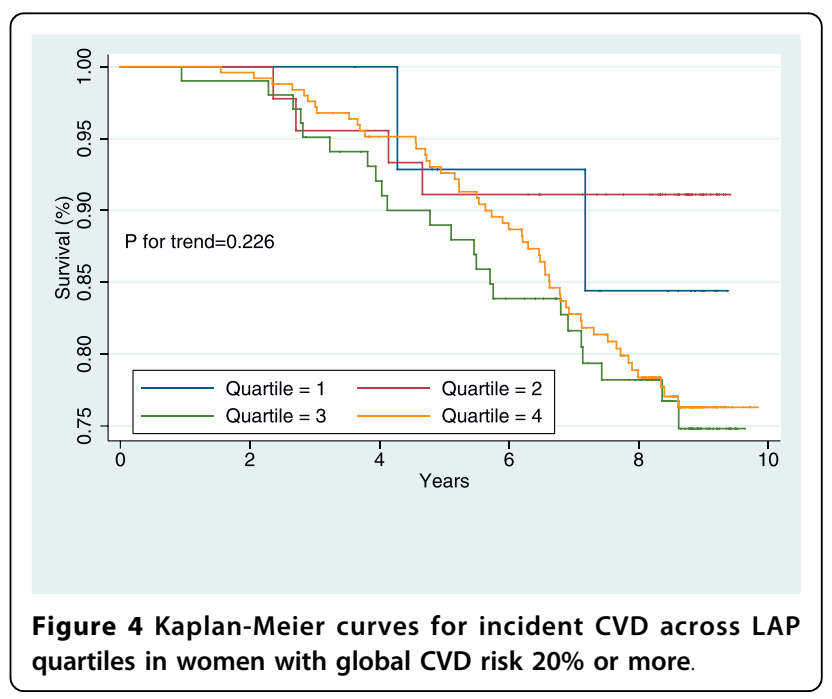




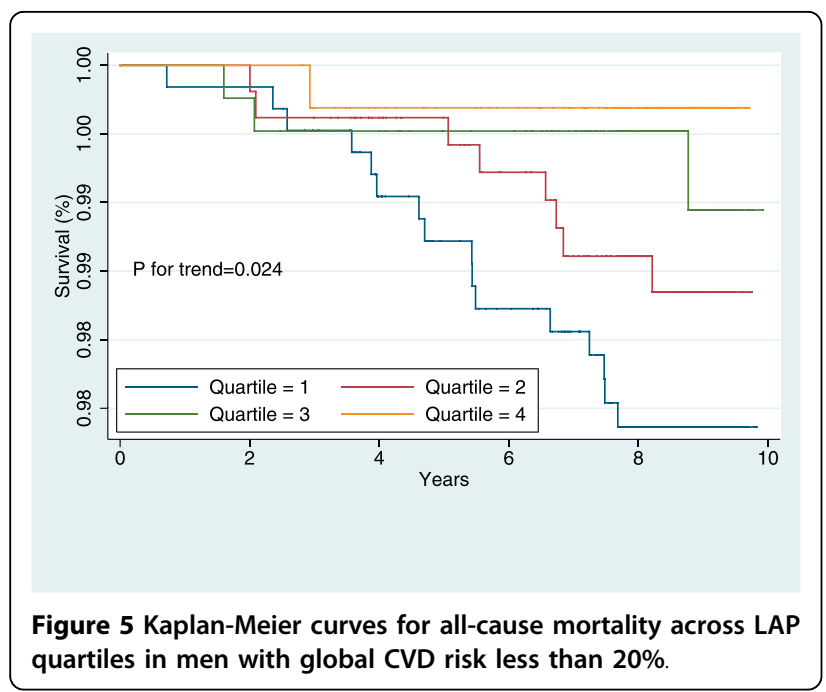

capacity and the calibration. Trade-offs between bias and variance (AIC and BIC), due to incorporating LAP into multivariate predictive models was similar to those due to BMI, WHpR, or WHtR.

Some studies recently compared different anthropometric measures in terms of their ability to predict CVD. They observed that measures of central and overall adiposity predicted CVD to a similar degree except for slight superiority for WHpR [49-52].

Nearly one-third of the population in the industrialized world are currently affected by obesity [53]. Whether obesity exerts independent and direct effects on CVD beyond its strong association with established clinical risk factors remains controversial [54]. Currently used risk functions for the prediction of coronary events in the general population do not include measures of excess body weight because it is considered to affect risk indirectly through more proximal physiological and

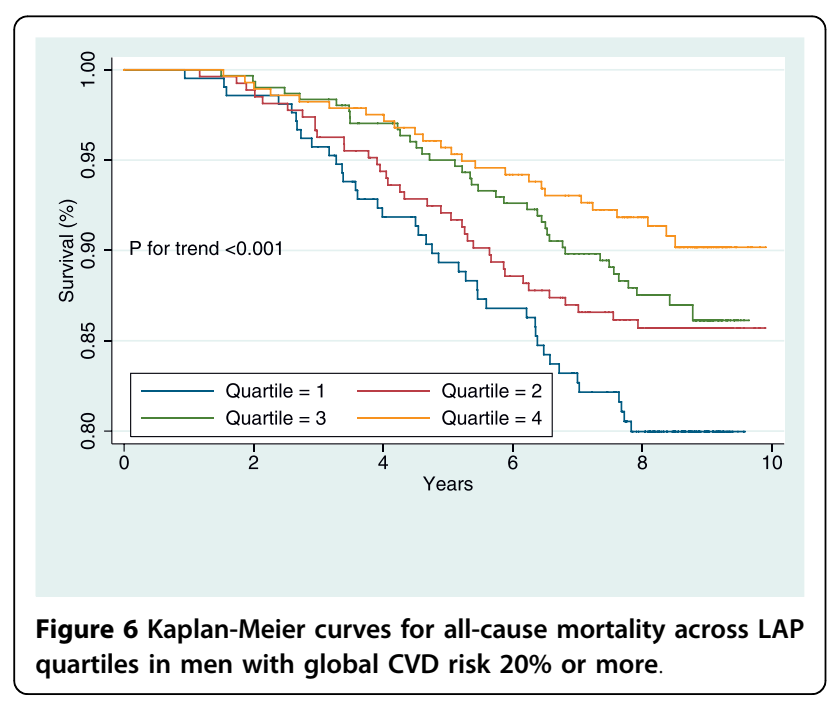

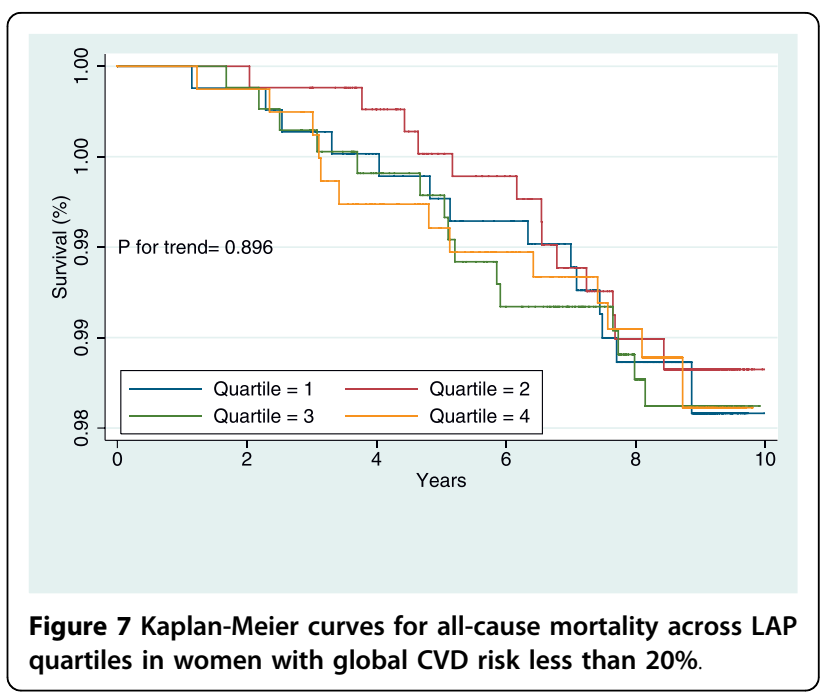

metabolic factors such as blood pressure, lipid levels, and diabetes [55]. Traditionally, anthropometric measures such as BMI or WC have been used to quantify adiposity. Results from the present study support other studies that have found that "obesity predicts risk of CVD incidence beyond the established clinical conditions" [54]. Abdominal visceral adipose tissue (VAT) has been highlighted as unique, pathogenic fat depots $[56,57]$. VAT is hypothesized to have a systemic effect on atherosclerosis. LAP, has been reported to offer an inexpensive and non invasive tool to estimate total body lipid accumulation in comparison with sophisticated imaging methods for estimating the lipid burden or uptake in isolated tissues [21]. The fact that, unlike LAP, the MetS components are not used as continuous variables makes these screening tools less than ideal for the optimal diagnosis of the cardio-metabolic risk [8]. It is commonly believed that only new calculators

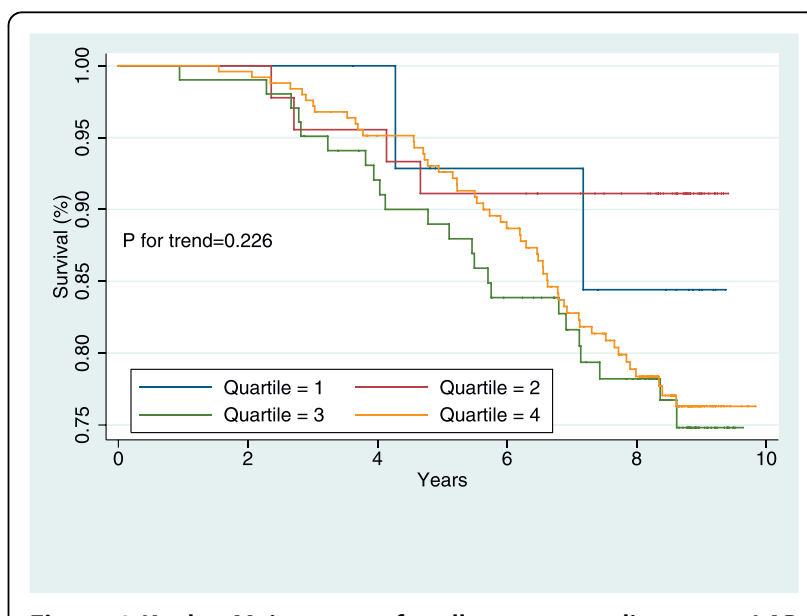

Figure 8 Kaplan-Meier curves for all-cause mortality across LAP quartiles in women with global CVD risk $20 \%$ or more. 
Table 5 Contribution of LAP to the risk of CVD and all-cause mortality, independent of common CVD risk factors

\begin{tabular}{|c|c|c|c|c|c|}
\hline & & \multicolumn{2}{|c|}{ Men } & \multicolumn{2}{|c|}{ Women } \\
\hline & & $\mathrm{HR}^{*}(95 \% \mathrm{Cls})$ & P-value & $\mathrm{HR}^{*}(95 \% \mathrm{Cls})$ & P-value \\
\hline \multirow[t]{2}{*}{ CVD } & Global CVD risk ${ }^{\dagger}<20 \%$ & $1.07(0.80-1.42)$ & 0.643 & $1.46(1.05-2.03)$ & 0.025 \\
\hline & Global CVD risk ${ }^{\dagger} \geq 20 \%$ & $1.09(0.90-1.32)$ & 0.374 & $1.20(0.75-1.92)$ & 0.440 \\
\hline \multirow[t]{2}{*}{ All-cause mortality } & Global CVD risk $^{\dagger}<20 \%$ & $0.75(0.52-1.08)$ & 0.128 & $0.74(0.48-1.15)$ & 0.183 \\
\hline & Global CVD risk ${ }^{\dagger} \geq 20 \%$ & $0.80(0.62-1.01)$ & 0.064 & $1.17(0.54-2.57)$ & 0.688 \\
\hline \multirow[t]{2}{*}{ CVD } & Assigned to the intervention & $1.58(1.11-2.26)$ & 0.011 & $1.43(0.89-2.29)$ & 0.143 \\
\hline & Not assigned to the intervention & $1.01(0.82-0.1 .25)$ & 0.896 & $1.33(0.90-1.96)$ & 0.148 \\
\hline \multirow[t]{2}{*}{ All-cause mortality } & Assigned to the intervention & $0.71(0.49-1.02)$ & 0.061 & $1.16(0.62-2.15)$ & 0.641 \\
\hline & Not assigned to the intervention & $0.77(0.61-0.98)$ & 0.034 & $0.73(0.44-1.20)$ & 0.214 \\
\hline
\end{tabular}

* For one SD increment in each continuous predictor, obtained from multivariate Cox proportional hazards regression model adjusted for age, smoking, systolic blood pressure, family history of premature CVD, diabetes, antihypertensive drug usage, HDL and non-HDL cholesterol, FPG, and $2 \mathrm{~h}-\mathrm{PCPG}$, plus the TLGS intervention measures.

tcalculated using "the Framingham general CVD prediction algorithm". (D'Agostino RB, Sr., Vasan RS, Pencina MJ, Wolf PA, Cobain M, Massaro JM, Kannel WB: General Cardiovascular Risk Profile for Use in Primary Care: The Framingham Heart Study. Circulation 2008, 117:743-753)

CVD, cardiovascular disease; FPG, fasting plasma glucose; HDL-C, high density lipoprotein cholesterol; HR, hazard ratio; LAP, lipid accumulation product; Ln, naturally logarithmically transformed; $2 \mathrm{~h}-\mathrm{PCPG}$, 2-hour post-challenge plasma glucose;

providing a continuous score could address this issue [58] and LAP has been developed on such a background. We observed, however, that if LAP is to be used for predicting CVD, it might not be superior to WHtR or WHpR.

Our results confirm the association of LAP with CVD risk factors. LAP increased risk of incident CVD among women. The same finding has been previously reported [59]. LAP predicted CVD risk only among men who were assigned to the lifestyle modification interventions. LAP may not predict CVD risk among men who are already at increased risk for CVD. We failed to demonstrate any association with increased risk of all-cause mortality due to LAP. In fact, after adjustment with CVD risk factors, LAP came to be inversely associated with risk of all-cause mortality. This association, however, was statistically significant among men (HR 0.74, 95\% CIs 0.61-0.90) but not among women (HRs 0.94 95\% CIs 0.74-1.20). This negative confounding would not be underappreciated. No clear-cut explanation, though, is readily available and confirmation in an independent study is required before this surprising observation could be understood. There is, to our knowledge, only one other study (PreCIS data base study), in which LAP has been found to be independently associated with increased mortality in both sexes. In the PreCIS

Table 6 Predictive accuracy of the LAP as compared with those of BMI, WHpR, and WHtR

\begin{tabular}{|c|c|c|c|c|c|c|c|}
\hline Factor & & $\mathrm{HR}^{*}(95 \% \mathrm{Cls})$ & 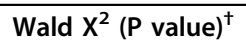 & AIC & $\mathrm{BIC}$ & Discrimination $^{*}$ & Calibration" \\
\hline \multicolumn{8}{|l|}{ Male } \\
\hline & LAP & $1.06(0.89-1.26)$ & - & 3134 & 3204 & $0.785(0.756-0.813)$ & $21.6(0.010)$ \\
\hline & $\mathrm{BMI}$ & $1.12(0.94-1.33)$ & $0.51(0.474)$ & 3133 & 3203 & $0.785(0.759-0.811)$ & $18.4(0.031)$ \\
\hline & WHpR & $1.25(1.06-1.47)$ & $4.62(0.032)$ & 3128 & 3198 & $0.788(0.762-0.814)$ & $18.0(0.035)$ \\
\hline & $\mathrm{WHtR}$ & $1.20(1.00-1.43)$ & $2.69(0.101)$ & 3131 & 3201 & $0.787(0.759-0.814)$ & $15.1(0.088)$ \\
\hline \multicolumn{8}{|l|}{ Female } \\
\hline & LAP & $1.41(1.02-1.96)$ & - & 1876 & 1947 & $0.846(0.818-0.875)$ & $12.2(0.201)$ \\
\hline & BMI & $1.15(0.97-1.37)$ & $0.81(0.367)$ & 1878 & 1951 & $0.847(0.825-0.868)$ & $12.8(0.170)$ \\
\hline & WHpR & 1.35 (1.10-1.65) & $0.13(0.718)$ & 1872 & 1945 & $0.848(0.820-0.876)$ & $11.9(0.218)$ \\
\hline & $\mathrm{WHtR}$ & $1.30(1.08-1.57)$ & $0.17(0.680)$ & 1873 & 1946 & $0.849(0.825-0.873)$ & $12.6(0.180)$ \\
\hline
\end{tabular}

* Hazard ratios for one SD increment in each anthropometric variable and one SD increment in log LAP level, obtained from multivariate Cox proportional hazard regression model adjusted for age, smoking, systolic blood pressure, family history of premature CVD, diabetes, smoking, antihypertensive drug usage, HDL and non-HDL cholesterol, FPG, and 2h-PCPG , plus the TLGS intervention measures

† Wald tests $X^{2}$ (P value) of the linear hypotheses concerning the Cox regression models coefficients (paired homogeneity test) were performed to test the null hypotheses that the hazard ratios (effect size) for LAP were equal to those for BMI, WHpR, or WHtR.

$¥$ Assessed with C statistic (95\% Cls)

I Assessed with Hosmer-Lemeshow $X^{2}$ (P value)

Abbreviations: AIC: Akaike information criteria; BIC: Bayesian information criteria; BMI: body mass index; LAP: lipid accumulation product; WHpR: waist-to-hip ratio; WHtR: waist-to-height ratio;

Standard deviations: Men $\rightarrow$ LAP (mmol.cm) (naturally logarithmically-transformed), 1.15; BMI (kg.m ${ }^{-2}$ ), 3.9; WHpR (\%)7.0;WHtR 6.5 (\%)

Standard deviations: Women $\rightarrow$ LAP (mmol.cm) (naturally logarithmically-transformed), 0.81; BMl (kg.m ${ }^{-2}$ ), 4.7; WHpR (\%)8.3;WHtR 8.1 (\%) 
population, LAP was reported to be associated with allcause mortality and the association was stronger among women than among men [59]. The proportion of CVD deaths in all deaths can explain the discrepancy, since only $36.6 \%$ of deaths in the TLGS were attributable to the CVD while the PreCIS population is known to be at increased risk of mortality from CVD. As compared to the TLGS, the PreCIS population were older (mean age 55 years) and at a greater risk of CVD; the prevalence of hypertension, diabetes, family history of CVD, and CVD were $65,19,42$, and $59 \%$ respectively [59]. The corresponding figures in the TLGS population were 24, 17.1, 6.2 , and $10.3 \%$, respectively. Differences in the baseline LAP from one cohort to another may also account for different findings. Other possible explanations may be the covariance of obesity with other CVD risk factors, unmeasured confounders, or misclassification bias from use of surrogate markers of obesity $[53,56]$.

WC was not associated with increased all-cause mortality among the TLGS' men or women. In previous studies showing the association between WC and mortality, the association was stronger for CVD mortality than overall mortality [59]. Among men, we observed TG to be inversely associated with all-cause mortality (HR 0.75, 95\% CIs 0.56-1.00); WC showed no association with mortality (HR 0.90, 95\% CIs 0.72-1.12). Difference in methods used to measure WC in different studies could at least partly describe the difference in the results obtained. The consequences of elevated TGs are controversial and the benefit of reducing these levels is yet to be clarified. Inverse or lack of association between TGs levels and all-cause mortality has previously been reported [60,61]. Men have been shown to be resistive to hazards of adiposity; and mild-grade central obesity has been reported to be protective [51]. Lower TGs levels resulting from malnourishment, combined with lower $\mathrm{WC}$ due to recent weight loss related to chronic illness might have biased our findings. In developing countries mortalities are still more likely to be due to chronic inflammations, undernourishment, or cancers than CVDs, and therefore, may be less likely to be associated with CVD risk factors including LAP $[62,63]$. Some investigators argued that introduction of both HDL-C and TGs as independent covariates in a model is inappropriate owing to multicollinearity and an intimate correlation between these variables in lipid metabolism [64]. However, even after we excluded HDL-C from analyses the results remained essentially unchanged (data not shown).

Strength of the present study lies in its prospective nature, the use of a large population-based-cohort of both sexes, accurate and valid data on risk factors at baseline, continuous surveillance of mortality and CVD events based on standard criteria.

Some limitations to our study merit mentioning. First, in this study, no data was available about TGs lowering drugs. Second, the small number of incident events precluded stratification of analyses by age. Third, sub-group samples might not have enough statistical power to detect effects. Finally, the population studied was of Persian ancestry, our results, thus, cannot be readily extrapolated to other populations.

\section{Conclusion}

We demonstrated that the LAP was independently associated with an increased risk of incident CVD among women and that the magnitude of this risk due to LAP was not significantly higher than those due to BMI, WHpR, or WHtR. However, among men, after controlling common CVD risk factors, we observed that LAP was not associated with any significant increased risk of incident CVD, except for those assigned to the lifestyle modification interventions. Among men, the magnitude of risk conferred by WHpR exceeded that conferred by LAP. No association was observed between the LAP and increased risk of all-cause mortality in women. Among men, LAP was inversely associated with all-cause mortality. If LAP is to be used for predicting CVD, it might not be superior to WHtR or WHpR.

\section{Acknowledgements}

This study was supported by grant No. 121 from the National Research Council of the Islamic Republic of Iran. We express our appreciation to the participants of district-13 of Tehran for their enthusiastic support in this study.

\section{Author details}

${ }^{1}$ Prevention of Metabolic Disorders Research Center, Research Institute for Endocrine Sciences (RIES), Shahid Beheshti University (M.C.), Tehran, Iran.

${ }^{2}$ Endocrine Research Center, Research Institute for Endocrine Sciences (RIES), Shahid Beheshti University (M.C.), Tehran, Iran.

\section{Authors' contributions}

MB designed the study, performed the statistical analysis, interpreted the analyses and drafted the manuscript. FH interpreted the analyses and revised the manuscript critically for important intellectual content. FA revised the manuscript critically for important intellectual content. All authors read and approved the final manuscript.

\section{Competing interests}

The authors declare that they have no competing interests.

Received: 17 July 2010 Accepted: 16 September 2010

Published: 16 September 2010

\section{References}

1. Reaven GM: Banting lecture 1988. Role of insulin resistance in human disease. Diabetes 1988, 37:1595-1607.

2. Ducimetiere P, Eschwege E, Papoz L, Richard JL, Claude JR, Rosselin G: Relationship of plasma insulin levels to the incidence of myocardial infarction and coronary heart disease mortality in a middle-aged population. Diabetologia 1980, 19:205-210. 
3. Welborn TA, Wearne $K$ : Coronary heart disease incidence and cardiovascular mortality in Busselton with reference to glucose and insulin concentrations. Diabetes care 1979, 2:154-160.

4. Pyöräla K: Relationship of glucose tolerance and plasma insulin to the incidence of coronary heart disease: results from two population studies in Finland. Diabetes care 1979, 2:131-141.

5. Fontbonne A, Charles MA, Thibult N, Richard JL, Claude JR, Warnet JM, Rosselin GE, Eschwège E: Hyperinsulinaemia as a predictor of coronary heart disease mortality in a healthy population: the Paris Prospective Study, 15-year follow-up. Diabetologia 1991, 34:356-361.

6. Bonora E, Formentini G, Calcaterra F, Lombardi S, Marini F, Zenari L, Saggiani F, Poli M, Perbellini S, Raffaelli A, et al: HOMA-Estimated Insulin Resistance Is an Independent Predictor of Cardiovascular Disease in Type 2 Diabetic Subjects. Diabetes care 2002, 25:1135-1141.

7. McFarlane SI, Banerji M, Sowers JR: Insulin Resistance and Cardiovascular Disease. The Journal of clinical endocrinology and metabolism 2001, 86:713-718.

8. Despres JP, Lemieux I, Bergeron J, Pibarot P, Mathieu P, Larose E, RodesCabau J, Bertrand OF, Poirier P: Abdominal Obesity and the Metabolic Syndrome: Contribution to Global Cardiometabolic Risk. Arterioscler Thromb Vasc Biol 2008, 28:1039-1049.

9. Alberti KG, Zimmet P, Shaw J: Metabolic syndrome-a new world-wide definition. A Consensus Statement from the International Diabetes Federation. Diabet Med 2006, 23:469-480.

10. Alberti KGMM, Eckel RH, Grundy SM, Zimmet PZ, Cleeman II, Donato KA, Fruchart JC, James WPT, Loria CM, Smith SC Jr: Harmonizing the Metabolic Syndrome. A Joint Interim Statement of the International Diabetes Federation Task Force on Epidemiology and Prevention; National Heart, Lung, and Blood Institute; American Heart Association; World Heart Federation; International Atherosclerosis Society; and International Association for the Study of Obesity. Circulation 2009, CIRCULATIONAHA.109.192644.

11. Alberti KG, Zimmet PZ: Definition, diagnosis and classification of diabetes mellitus and its complications. Part 1: diagnosis and classification of diabetes mellitus provisional report of a WHO consultation. Diabet Med 1998, 15:539-553.

12. Executive Summary of The Third Report of The National Cholesterol Education Program (NCEP) Expert Panel on Detection, Evaluation, And Treatment of High Blood Cholesterol In Adults (Adult Treatment Panel III). 2001, 285:2486-2497.

13. Grundy SM: Metabolic Syndrome Scientific Statement by the American Heart Association and the National Heart, Lung, and Blood Institute. Arterioscler Thromb Vasc Biol 2005, 25:2243-2244.

14. Einhorn D, Reaven GM, Cobin RH, Ford E, Ganda OP, Handelsman Y, Hellman R, Jellinger PS, Kendall D, Krauss RM, et al: American College of Endocrinology position statement on the insulin resistance syndrome. Endocr Pract 2003, 9:237-252.

15. Reaven G, Abbasi F, McLaughlin T: Obesity, Insulin Resistance, and Cardiovascular Disease. Recent Prog Horm Res 2004, 59:207-223.

16. Grundy SM, Brewer HB Jr, Cleeman Jl, Smith SC Jr, Lenfant C: Definition of metabolic syndrome: Report of the National Heart, Lung, and Blood Institute/American Heart Association conference on scientific issues related to definition. Circulation 2004, 109:433-438.

17. Despres JP, Lemieux I: Abdominal obesity and metabolic syndrome. Nature 2006, 444:881-887.

18. Reaven GM: The individual components of the metabolic syndrome: is there a raison d'etre? J Am Coll Nutr 2007, 26:191-195.

19. Unger RH: Lipid overload and overflow: metabolic trauma and the metabolic syndrome. Trends Endocrinol Metab 2003, 14:398-403.

20. Kahn HS: The "lipid accumulation product" performs better than the body mass index for recognizing cardiovascular risk: a population-based comparison. BMC Cardiovasc Disord 2005, 5:26.

21. Kahn HS: The lipid accumulation product is better than BMI for identifying diabetes: a population-based comparison. Diabetes care 2006, 29:151-153.

22. Kahn HS, Valdez R: Metabolic risks identified by the combination of enlarged waist and elevated triacylglycerol concentration. Am J Clin Nutr 2003, 78:928-934

23. Lemieux I, Pascot A, Couillard C, Lamarche B, Tchernof A, Almeras N, Bergeron J, Gaudet D, Tremblay G, Prud'homme D, et al: Hypertriglyceridemic waist: A marker of the atherogenic metabolic triad (hyperinsulinemia; hyperapolipoprotein B; small, dense LDL) in men? Circulation 2000, 102:179-184.

24. Bozorgmanesh $M$, Hadaegh F, Azizi F: Diabetes prediction, lipid accumulation product, and adiposity measures; 6-year follow-up: Tehran lipid and glucose study. Lipids Health Dis 2010, 9:45.

25. loachimescu AG, Brennan DM, Hoar BM, Hoogwerf BJ: The Lipid Accumulation Product and All-cause Mortality in Patients at High Cardiovascular Risk: A PreCIS Database Study. Obesity (Silver Spring) 2009, 18(9):1836-44.

26. Azizi F, Ghanbarian A, Momenan AA, Hadaegh F, Mirmiran P, Hedayati M, Mehrabi Y, Zahedi-As| S: Prevention of non-communicable disease in a population in nutrition transition: Tehran Lipid and Glucose Study phase II. Trials 2009, 10:5

27. Freedman DS, Kahn HS, Mei Z, Grummer-Strawn LM, Dietz WH, Srinivasan SR, Berenson GS: Relation of body mass index and waist-toheight ratio to cardiovascular disease risk factors in children and adolescents: the Bogalusa Heart Study. Am J Clin Nutr 2007, 86:33-40.

28. Hadaegh F, Harati H, Ghanbarian A, Azizi F: Association of total cholesterol versus other serum lipid parameters with the short-term prediction of cardiovascular outcomes: Tehran Lipid and Glucose Study. Eur J Cardiovasc Prev Rehabil 2006, 13:571-577.

29. Gibbons RJ, Abrams J, Chatterjee K, Daley J, Deedwania PC, Douglas JS, Ferguson TB Jr, Fihn SD, Fraker TD Jr, Gardin JM, et al: ACC/AHA 2002 Guideline Update for the Management of Patients With Chronic Stable Angina-Summary Article: A Report of the American College of Cardiology/American Heart Association Task Force on Practice Guidelines (Committee on the Management of Patients With Chronic Stable Angina). Circulation 2003, 107:149-158.

30. Braunwald E, Antman EM, Beasley JW, Califf RM, Cheitlin MD, Hochman JS, Jones RH, Kereiakes D, Kupersmith J, Levin TN, et al: ACC/AHA Guideline Update for the Management of Patients With Unstable Angina and NonST-Segment Elevation Myocardial Infarction-2002: Summary Article: A Report of the American College of Cardiology/American Heart Association Task Force on Practice Guidelines (Committee on the Management of Patients With Unstable Angina). Circulation 2002, 106:1893-1900.

31. Redberg RF, Benjamin EJ, Bittner V, Braun LT, Goff DC Jr, Havas S, Labarthe DR, Limacher MC, Lloyd-Jones DM, Mora S, et al: ACCF/AHA 2009 performance measures for primary prevention of cardiovascular disease in adults: a report of the American College of Cardiology Foundation/ American Heart Association task force on performance measures (writing committee to develop performance measures for primary prevention of cardiovascular disease): developed in collaboration with the American Academy of Family Physicians; American Association of Cardiovascular and Pulmonary Rehabilitation; and Preventive Cardiovascular Nurses Association: endorsed by the American College of Preventive Medicine, American College of Sports Medicine, and Society for Women's Health Research. Circulation 2009, 120:1296-1336.

32. Chobanian AV, Bakris GL, Black HR, Cushman WC, Green LA, Izzo JL Jr, Jones DW, Materson BJ, Oparil S, Wright JT Jr, Roccella EJ: The Seventh Report of the Joint National Committee on Prevention, Detection, Evaluation, and Treatment of High Blood Pressure: The JNC 7 Report JAMA 2003, 289(19):2560-2572.

33. Third Report of the National Cholesterol Education Program (NCEP) Expert Panel on Detection, Evaluation, and Treatment of High Blood Cholesterol in Adults (Adult Treatment Panel III) Final Report. 2002, 106:3143.

34. Genuth S, Alberti KG, Bennett P, Buse J, Defronzo R, Kahn R, Kitzmiller J, Knowler WC, Lebovitz $H$, Lernmark $A$, et al: Follow-up report on the diagnosis of diabetes mellitus. Diabetes care 2003, 26:3160-3167.

35. D'Agostino RB Sr, Vasan RS, Pencina MJ, Wolf PA, Cobain M, Massaro JM, Kannel WB: General Cardiovascular Risk Profile for Use in Primary Care: The Framingham Heart Study. Circulation 2008, 117:743-753.

36. Hanley JA, McNeil BJ: The meaning and use of the area under a receiver operating characteristic (ROC) curve. Radiology 1982, 143:29-36.

37. Harrell FE Jr, Lee KL, Mark DB: Multivariable prognostic models: issues in developing models, evaluating assumptions and adequacy, and measuring and reducing errors. Stat Med 1996, 15:361-387.

38. Hlatky MA, Greenland P, Arnett DK, Ballantyne CM, Criqui MH, Elkind MSV, Go AS, Harrell FE Jr, Hong Y, Howard BV, et al: Criteria for Evaluation of 
Novel Markers of Cardiovascular Risk: A Scientific Statement From the American Heart Association. Circulation 2009, 119:2408-2416.

39. D'Agostino RB, Nam BH: Evaluation of the performance of survival analysis models: Discrimination and Calibration measures. In Handbook of Statistics, Survival Methods. Edited by: Balakrishnan N, Rao CR. Amsterdam, The Netherlands: Elsevier B.V; 2004:23:1-25.

40. Hosmer DW, Lemeshow S: Applied logistic regression Wiley-Interscience 2000.

41. Hosmer DW, Lemeshow S, May S: Applied survival analysis: regression modeling of time-to-event data. Hoboken, N.J.: Wiley-Interscience, 2.

42. Grønnesby JK, Borgan Ø: A method for checking regression models in survival analysis based on the risk score. Lifetime Data Analysis 1996, 2:315-328.

43. May S, Hosmer DW: A simplified method of calculating an overall goodness-of-fit test for the Cox proportional hazards model. Lifetime Data Analysis 1998, 4:109-120.

44. May S, Hosmer DW: A Cautionary Note on the Use of the Grønnesby and Borgan Goodness-of-Fit Test for the Cox Proportional Hazards Model. Lifetime Data Analysis 2004, 10:283-291.

45. Parzen M, Lipsitz SR: A global goodness-of-fit statistic for Cox regression models. Biometrics 1999, 55:580-584.

46. Akaike H: A new look at the statistical model identification. IEEE Trans Automat Contr 1974, AC-19:716-723.

47. Schwarz G: Estimating the dimension of a model. The Annals of Statistics $1978,461-464$

48. Abbate LM, Stevens J, Schwartz TA, Renner JB, Helmick CG, Jordan JM: Anthropometric measures, body composition, body fat distribution, and knee osteoarthritis in women. Obesity (Silver Spring) 2006, 14:1274-1281.

49. Hadaegh F, Zabetian A, Sarbakhsh P, Khalili D, James WP, Azizi F: Appropriate cutoff values of anthropometric variables to predict cardiovascular outcomes: 7.6 years follow-up in an Iranian population. Int J Obes (Lond) 2009, 33:1437-1445.

50. Pischon T, Boeing H, Hoffmann K, Bergmann M, Schulze MB, Overvad K, van der Schouw YT, Spencer E, Moons KGM, Tjonneland A, et al: General and Abdominal Adiposity and Risk of Death in Europe. The New England journal of medicine 2008, 359:2105-2120.

51. Auyeung TW, Lee JSW, Leung J, Kwok T, Leung PC, Woo J: Survival in Older Men May Benefit From Being Slightly Overweight and Centrally Obese-A 5-Year Follow-up Study in 4,000 Older Adults Using DXA. The Journals of Gerontology Series A: Biological Sciences and Medical Sciences 2010, 65A:99-104.

52. Poirier P: Adiposity and cardiovascular disease: are we using the right definition of obesity? European Heart Journal 2007, 28:2047-2048.

53. Poirier P, Giles TD, Bray GA, Hong Y, Stern JS, Pi-Sunyer FX, Eckel RH: Obesity and Cardiovascular Disease: Pathophysiology, Evaluation, and Effect of Weight Loss: An Update of the 1997 American Heart Association Scientific Statement on Obesity and Heart Disease From the Obesity Committee of the Council on Nutrition, Physical Activity, and Metabolism. Circulation 2006, 113:898-918.

54. Jensen MK, Chiuve SE, Rimm EB, Dethlefsen C, Tjonneland A, Joensen AM, Overvad K: Obesity, Behavioral Lifestyle Factors, and Risk of Acute Coronary Events. Circulation 2008, 117:3062-3069.

55. Wilson PWF, D'Agostino RB, Levy D, Belanger AM, Silbershatz H, Kannel WB: Prediction of Coronary Heart Disease Using Risk Factor Categories. Circulation 1998, 97:1837-1847.

56. Poirier P, Despres JP: Waist circumference, visceral obesity, and cardiovascular risk. J Cardiopulm Rehabil 2003, 23:161-169.

57. Fox CS, Massaro JM, Hoffmann U, Pou KM, Maurovich-Horvat P, Liu CY, Vasan RS, Murabito JM, Meigs JB, Cupples LA, et al: Abdominal Visceral and Subcutaneous Adipose Tissue Compartments: Association With Metabolic Risk Factors in the Framingham Heart Study. Circulation 2007, 116:39-48

58. Sattar N: The metabolic syndrome: should current criteria influence clinical practice? Curr Opin Lipidol 2006, 17:404-411.

59. Ioachimescu AG, Brennan DM, Hoar BM, Hoogwerf BJ: The Lipid Accumulation Product and All-cause Mortality in Patients at High Cardiovascular Risk: A PreCIS Database Study. Obesity 2009.

60. Kovesdy CP, Anderson JE, Kalantar-Zadeh K: Inverse association between lipid levels and mortality in men with chronic kidney disease who are not yet on dialysis: effects of case mix and the malnutritioninflammation-cachexia syndrome. J Am Soc Nephrol 2007, 18:304-311.
61. Stensvold I, Tverdal A, Urdal P, Graff-Iversen S: Non-fasting serum triglyceride concentration and mortality from coronary heart disease and any cause in middle aged Norwegian women. BMJ 1993, 307:1318-1322.

62. Murray C, Lopez A: Global mortality, disability, and the contribution of risk factors: Global Burden of Disease Study. The Lancet 1997, 349:1436-1442.

63. Lopez AD, Mathers CD, Ezzati M, Jamison DT, Murray CJL: Global and regional burden of disease and risk factors, 2001: systematic analysis of population health data. The Lancet 2006, 367:1747-1757.

64. Haim M, Benderly M, Brunner D, Behar S, Graff E, Reicher-Reiss H, Goldbourt U: Elevated Serum Triglyceride Levels and Long-Term Mortality in Patients With Coronary Heart Disease: The Bezafibrate Infarction Prevention (BIP) Registry. Circulation 1999, 100:475-482.

\section{doi:10.1186/1476-511X-9-100}

Cite this article as: Bozorgmanesh et al.: Predictive performances of lipid accumulation product vs. adiposity measures for cardiovascular diseases and all-cause mortality, 8.6-year follow-up: Tehran lipid and glucose study. Lipids in Health and Disease 2010 9:100.

\section{Submit your next manuscript to BioMed Central and take full advantage of:}

- Convenient online submission

- Thorough peer review

- No space constraints or color figure charges

- Immediate publication on acceptance

- Inclusion in PubMed, CAS, Scopus and Google Scholar

- Research which is freely available for redistribution

Submit your manuscript at www.biomedcentral.com/submit
Ciomed Central 